\title{
Application of Multiply Regression Linear Model and New Technology Method in Estimating Learning and Education of Students
}

\author{
Zainb Hassan Radhy ${ }^{1 *}$ \\ ${ }^{1}$ Department of Mathematical Statistics, College of Computer Science and Information Technology University of Al-Qadisiyah, \\ IRAQ \\ *CORRESPONDENCE: Z Zainb.hassan@qu.edu.iq
}

\begin{abstract}
The Linear multiple regression model is one of the prediction models whose parametric estimations could be achieved in different methods. With the advent of modern technologies and modern information technologies and its impact on various aspects of life, using it as a tool to facilitate learning in all the courses, and in particular mathematics, is inevitable. Meanwhile, the key role of the teacher in the teaching-learning process, the need for teachers to prepare teachers to face the diversity of existing technologies, to measure and identify efficient tools and apply them to teaching, undeniably undeniable. Which will be very complicated. In order to prepare for the teaching of mathematics, their teachers must have a profound and broad understanding of the subjects and mathematical subjects in order to be able to generalize and understand the content and educational technology of technology, to what Meaning of education along with technology. In fact, the need for the interference between the two areas of mathematics and technology is the dominance of teachers in both domains. In other words, teaching along with technology means that as long as the teacher thinks about specific mathematical concepts, one must simultaneously contemplate how to make mathematical concepts comprehensible to his students using the technology of expression In this research, we have tried to highlight the role of teachers in identifying the achievements of using technology in mathematics education in order to better realize this important issue.
\end{abstract}

Keywords: mathematical education, technology, new teaching methods, mathematical teachers

\section{INTRODUCTION}

For any statistician, it is important to study the regression analysis and analyzing the effect of independent variable on the dependent variable. Nowadays, the management and planning for human resources is one of the significant impacts which have a crucial effect on economic success for any industrial project. Many approaches to achieve this goal of study have been presented such as; techniques which are based on artificial programming, models of mathematical simulation, and inferential statistics (Çetin and Sarucan 2015).

The goal programming theory also has a remarkable contribution in this field of study. Cetin and Sarucan (2015) mentioned that the application of goal programming is still possessing a leading position in solving the decision making problems which have multi objectives. Rahman et al. (2018) pointed out that the GP is an effective approach which is primarily applied to obtain compromised solutions to the engineering activities to implement the targeted design goals. Mahad et al. (2015) introduced a promised mathematical application for

Article History: Received 5 September $2018 \bullet$ Revised 23 October $2018 \bullet$ Accepted 6 December 2018

(C) 2019 by the authors; licensee Modestum Ltd., UK. Open Access terms of the Creative Commons Attribution 4.0 International License (http://creativecommons.org/licenses/by/4.0/) apply. The license permits unrestricted use, distribution, and reproduction in any medium, on the condition that users give exact credit to the original author(s) and the source, provide a link to the Creative Commons license, and indicate if they made any changes. 
goal programming technique, which is called Zero One Goal Programming, to find the optimum solution for a problem of multiple goals. This style for solving the programming problems was also presented by Lipske and Fletcher (1984) when it tried to solve the problem of selecting the most suitable reel of telephone cables by Western Electric Company. Jayaraman (2016) exploited the goal programming scheme in addressing the problem of the expected growth in the employment in different sectors of electricity generation and consumption directories in United Arab Emirates. A fuzzy goal programming approach was subject of study by Tyagi (2012) to solve the strategy of multiple objectives optimization problem in customer-driven marketing.

\section{AIM OF STUDY}

The proper use of educational technology in the teaching process - learning can lead to the improvement of teaching and learning outcomes. Using technology in the classroom involves a variety of ways that can be put into a range. Using PowerPoint on the one hand, and the use of mixed electronic learning systems on the other hand. In this case, all of the above modes may lead to improved teaching and learning enhancement. This study aimed to investigate the application of educational technology in teaching methods of mathematical education and students in the university.

\section{MULTIPLY REGRESSION LINEAR MODEL}

In this model suppose that the variable $y$ expresses the dependent variable, and the variables

$\left(x_{1}, x_{2}, \ldots, x_{k}\right)$ refer to $(\mathrm{k})$ of independent variables which draw from (n) observation number. Then the following linear function can be obtained:

$$
y_{i}=\beta_{0}+\beta_{1} x_{i 1}+\cdots+\beta_{k} x_{i k}+\varepsilon_{i}
$$

where $i=1,2, \ldots, n$ and $\varepsilon_{i}$ represents random errors which distribute normally with zero mean and $\sigma^{2}$ variance.

To simplify the mathematical operations, it is convenient to re-express the linear function in matrix form:

$$
\left[\begin{array}{c}
y_{1} \\
y_{2} \\
. \\
. \\
y_{n}
\end{array}\right]=\left[\begin{array}{ccccc}
1 & X_{11} & x_{12} & \ldots & x_{1 k} \\
1 & X_{21} & x_{22} & \ldots & x_{2 k} \\
\ldots & \ldots & \ldots . . & \ldots & \ldots \\
\ldots & \ldots & \ldots . . & \ldots & \ldots \\
1 & X_{n 1} & x_{n 2} & \ldots & x_{n k}
\end{array}\right]\left[\begin{array}{c}
\beta_{0} \\
\beta_{1} \\
\ldots \\
\ldots \\
\beta_{k}
\end{array}\right]+\left[\begin{array}{c}
\varepsilon_{0} \\
\varepsilon_{1} \\
\ldots \\
\ldots \\
\varepsilon_{k}
\end{array}\right]
$$

$Y:(n * 1)$ Column vector for dependent variables.

$X:(n *(k+1))$ Matrix for independent variables.

$B$ : Column vector for regression parameters $((k+1) * 1)$

$U$ : Column vector of errors $(n * 1)$

The linear multiple regression module depend on some supposes:

- Elements of the matrix $(X)$ represent the observation values.

- There is no linear relationship between the independent Variables, that means $\operatorname{Rank}(X)=(k+1)<$.

- The , s, column matrix is linear independent to error random vector $(U), \operatorname{cov}(X, U)=E(X U)-[E(X)][E(U)]$ $=0$

- Random Error $\left(\varepsilon_{i}, i=1,2, \ldots, n\right)$ has normal distribution $\varepsilon_{i} \sim N\left(0, \sigma^{2}\right)$

\section{EDUCATION TECHNOLOGY}

Continued assessment of classroom-based learning and the contribution of technology to its development. The use of modern educational technology does not mean the elimination of trainer and its replacement, but the use of technology means the optimal use of time and increased ability of the trainer to provide content, meditation In learning, promoting learners' motivation, studying and applying research, and increasing the power of using the power of reason in solving problems that are considered to be the learning philosophy and the underlying purpose of the classroom. What is certain, the use of educational technology is quite different 
Table 1. The results are related to the Cronbach's alpha coefficient

\begin{tabular}{lcc}
\hline Variables & Cronbach's alpha coefficient-1 & Cronbach's alpha coefficient-2 \\
\hline Hypothesis 1 & 0.793 & 0.818 \\
\hline Hypothesis 2 & 0.592 & 0.745 \\
\hline Hypothesis 3 & 0.921 & 0.940 \\
\hline
\end{tabular}

from the level of teaching and the type of lesson. The National Institute of Educational Technology in the United States continues with two main goals in the field of education systems: first, the design of educational technology for all levels of education, and the second, the provision of scientific opportunities for trainers in the use of educational technology. The title of a quality education service provider. Therefore, the main purpose of using modern educational technologies in learning geography is to defeat fences and create a new educational revolution. The most important problem and the barrier against this issue is traditional thinking and belief in outdated methods and the reluctance and understanding of the importance of using educational technology.

In relation to the subject of research, based on previous studies and research, the following hypotheses have been developed that are tested in the statistical society:

Hypothesis 1: Teaching method used by teachers makes students interested in learning and doing homework.

Hypothesis 2: Teachers, using teaching aids, define the content and goals of teaching better for students.

Hypothesis 3: Student learning capability increase by the technological tools.

\section{RESULT}

The designed questionnaire is in terms of content and symbolic (apparent) validity, approved by the relevant professors and professionals of the profession, including psychology. In this study, Cronbach's alpha coefficient was used to estimate reliability. A pre-test was conducted to determine the appropriate sample size and Cronbach's alpha. In this research, Cronbach's alpha coefficient was used to examine the level of homogeneity of questionnaires for the first part of the questionnaire (94\%) and for the second part (92.1\%), which shows that the questionnaire has good accuracy and reliability. The Cronbach's alpha coefficient is presented in Table 1 to examine the degree of homogeneity of the related questions of assumptions.

Given the strengths and impact of using technology in higher education, such as quick access to data, helping teachers in organizing, storing and developing data, improving student learning, improving the quality of research and education, and more. The following suggestions are provided:

1. Although research findings have shown that there is a good use of the use of educational technology in the teaching and learning process, for the up-to-date use of the professors, it is necessary to continuously train in this field. To provide faculty members with the latest findings in this field.

2. Managers of educational groups, especially the foreign language group, to improve the quality of field education Provide institutionalization of the following solutions more than once:

- Teaching workshops will be held.

- Invite successful faculty members in teaching for their successful experiences.

- In order to encourage members to improve their teaching quality, they provide a reward for successful experiences.

\section{CONCLUSION}

The present study was conducted to investigate the effect of the use of teaching aids and educational technology (specifically PowerPoint) on learning and teaching quality of students. The results of this research indicate that the teaching method used by the professors makes students interested in learning and doing assignments that other studies acknowledge. Teachers also identify the content and goals of teaching better for students by using educational aids. In addition, with the view that students who are studying in enriched environments receive more achievements, the use of these devices has led to better and deeper teaching of subjects. It will happen more. So, the results of some studies indicate that the use of educational technology increases the attention of students in learning. 


\section{Disclosure statement}

No potential conflict of interest was reported by the authors.

\section{Notes on contributors}

Zainb Hassan Radhy - Department of Mathematical Statistics, College of Computer Science and Information Technology University of Al-Qadisiyah, Iraq.

\section{REFERENCES}

Ahmad, M. H., Adnan, R., Kong, L. C., \& Daud, Z. M. (2005). Comparing Least - squares and goal programming Estimates of Linear Regression Parametric. Jilid, 21, Bil. 2, him, 101-112.

Çetin, E., \& Sarucan A. (2015). Nurse scheduling using binary fuzzy goal programming. In 6th International Conference on Modeling, Simulation, and Applied organization, Istanbul, Turkey (pp. 1-6).

Charnes, A., \& Cooper, W. (1961). Management Models and Industrial Application of Linear Programming, New York.

Charnes, A., \& Cooper, W. W. (1977). Goal Programming and Multiple Objectives Optimizations. European Journal of Operational Research, 1, 39-54. https://doi.org/10.1016/S0377-2217(77)81007-2

Degelae, A. L., \& Nbeal, L, (1997). Building the workforce planning model in the General Establishment for Electricity Distribution of Baghdad, Mustansiriya University.

Fikri. G. (2005). A Comparison of Three Linear Programming Models for Computing Least Absolute Values Estimation. J. of Math and Stat., v(34), 95-102.

Ignazio, J. P. (1976). Goal Programming and Extensions. Lexington, MA: Lexington Books.

Jayaraman, R. (2016). A Goal Programming Model with Satisfaction Function for Long-Run Sustainability in the United Arab Emirates. In IEEE International Conference on Industrial Engineering and Engineering Management (IEEM), Singapore (pp. 249-253).

Lehmann, E. L. (1988). Nonparametric Statically Methods Based on Ranks. San Francisco Holiday.

Lipske, K., Fletcher, J. (1984, April) A Nonlinear Zero-One Combinatorial, Goal Programming Model and Constructive Algorithm for Solving Multiobjective Assignment Problems. AT\&T BELL Laboratories Technical Journal, 63(4). https://doi.org/10.1002/j.1538-7305.1984.tb00025.x

Mahad, N., et al. (2015). The Application of Zero-One Goal Programming in Selecting the Optional Cocurriculum and Co-academic Activities in Primary School: A case study. In International Symposium on Mathematical Sciences and Computing Research, Malaysia (pp. 396-401). https://doi.org/10.1109/ISMSC.2015.7594087

Rahman, A., Sarno, R., \& Effendi, Y. (2018, March). Goal Programming to Optimize Time and Cost for each Activity in Port Container Handling. In International Conference on Information and Communications Technology, Yogyakarta, Indonesia (pp. 866-871). https://doi.org/10.1109/ICOIACT.2018.8350808

Tyagi, S. (2012, November). A Fuzzy Goal Programming Approach for Optimal Product Family Design of Mobile Phones and Multiple-Platform Architecture. IEEE Transactions on Systems, 42(6). 